\title{
O DESEMPENHO EM FOCO
}

\section{PERFORMANCE HIGHLIGHTED}

\author{
Letícia de Oliveira Neves ${ }^{1}$ \\ Universidade Estadual de Campinas, \\ Faculdade de Engenharia Civil, Arquitetura \\ e Urbanismo, \\ Campinas - SP \\ Editor-chefe \\ lneves@unicamp.br \\ Regina Coeli Ruschel ${ }^{2}$ \\ Universidade Estadual de Campinas, \\ Faculdade de Engenharia Civil, Arquitetura \\ e Urbanismo, \\ Campinas - SP \\ Editor-chefe \\ parc@fec.unicamp.br
}

\section{Editorial}

O quarto número do Volume 9 de 2018 da PARC Pesquisa em Arquitetura e Construção congrega artigos submetidos em fluxo contínuo, abrangendo a temática do desempenho das edificações no ambiente construído. Os artigos originais e de comunicação foram desenvolvidos por pesquisadores dos estados brasileiros de - Minas Gerais, Paraíba, Rio Grande do Norte, Rio Grande do Sul, Santa Catarina e São Paulo - e também do exterior - Suécia. As instituições de ensino e pesquisa envolvidas nos estudos apresentados são: Faculdades Integradas de Patos, Instituto de Pesquisas Tecnológicas do Estado de São Paulo, Lund University, Universidade Federal da Paraíba, Universidade Federal de Pelotas, Universidade Federal de Santa Catarina, Universidade Federal de Viçosa e Universidade Federal Rural do Semi-Árido. As áreas de formação dos autores concentram-se em Arquitetura e Urbanismo, na maioria, interagindo com Biólogo, Design de Interiores, Engenheiro Eletricista e Engenheiro Civil. As temáticas de desempenho desenvolvidas nos artigos relacionam-se, em sua grande maioria, ao desempenho térmico e energético de edificações, componentes construtivos e sistemas (quatro primeiros artigos), seguida pelo estudo de modelos de céu destinado à simulação de desempenho em iluminação natural de edificações (quinto artigo) e, por fim, apresentamos um estudo de verificação automática de conformidade a norma de desempenho NBR 15575: 2013 para edifícios residenciais com BIM (sexto artigo).

O primeiro artigo é dos autores Tatiane Ballerini Fernandes, Roseana Bonotto Ruivo, Eduardo Grala da Cunha, da Universidade Federal Pelotas; e Lisandra Fachinello Krebs, da Lund University. O artigo apresenta uma análise do desempenho termoenergético de diferentes coberturas vegetadas aplicadas em um edifício de escritórios na cidade de Pelotas, RS, zona bioclimática brasileira 2. A análise, realizada por meio de simulações computacionais no programa EnergyPlus, incluiu quatro cenários de cobertura verde, com diferentes alturas de substrato, e três cenários sem cobertura verde, com diferentes componentes construtivos para a cobertura, alterando absortância solar e transmitância térmica. A avaliação de resultados foi feita com base em dados de consumo de energia e fluxo térmico da edificação, mostrando um melhor desempenho termoenergético para a cobertura vegetada de maior espessura de substrato (50 $\mathrm{cm})$, tendo em vista sua elevada capacidade térmica $\left(882 \mathrm{~kJ} / \mathrm{m}^{2} . \mathrm{K}\right)$ e menor consumo anual de energia $(84,3 \mathrm{kWh} / \mathrm{m} 2$.ano). 
O artigo dos autores Emmily Gersica Santos Gomes e Aluísio Braz de Melo, da Universidade Federal da Paraíba, caracteriza o desempenho térmico de vedações verticais contendo blocos EVA em sua composição, por meio de análises comparativas entre amostras fabricadas com blocos EVA e amostras de componentes construtivos convencionais, como tijolos cerâmicos e blocos de concreto. A análise foi conduzida por meio de ensaios experimentais em câmara térmica e cálculos para caracterização do fluxo de calor das amostras. Os resultados permitiram verificar que o fluxo de calor característico dos blocos EVA se enquadra numa faixa entre $1.467 \mathrm{~W}$ e $1.808 \mathrm{~W}$, valores estes intermediários ao tijolo cerâmico $(1.276 \mathrm{~W})$ e ao bloco de concreto (2.511 W). Dentre os blocos EVA avaliados, a amostra com maior percentual do material (80\%) no compósito se destacou pelo menor fluxo de calor $(1.467 \mathrm{~W})$.

Thiago Toledo Viana Rodrigues, Joyce Correna Carlo e Delly Oliveira Filho, da Universidade Federal de Viçosa, apresentam um artigo na língua inglesa, em que se propõe um novo método de modelagem computacional das propriedades térmicas de sistemas fotovoltaicos semitransparentes (STPV), visando auxiliar na avaliação do desempenho térmico do ambiente simulado e do desempenho energético do sistema. $\mathrm{O}$ método foi desenvolvido no programa EnergyPlus e foi testado para diferentes configurações de esquadrias, em um protótipo teste. Os resultados obtidos nos modelos testados mostraram diferenças mais significativas no desempenho térmico do que energético, entre os cenários de esquadrias, com confirmação do caso mais usado na literatura como o caso de melhor desempenho; reforçando, assim, a confiança no método proposto.

Anderson Claro, da Universidade Federal de Santa Catarina, apresenta um novo método para determinar qual modelo de céu da norma ISO 15469- 2004 (E)-CIE S 011E 2003 mais se adequa aos dados originários, dentre um conjunto de possibilidades de modelos de céu disponibilizados pela norma e posteriormente tratados em artigos científicos. Os cálculos foram realizados com base no método da radiosidade, utilizando-se, como dados de entrada, dados de radiação de arquivos climáticos. Os testes incluíram arquivos de várias localidades no Brasil e em outros países, como França, Japão, EUA, chegando a resultados dentro de uma margem de aproximação bastante satisfatória, com divergências médias abaixo de
$10 \%$, em sua maioria, demonstrando a coerência do método.

Finalizamos este número com a comunicação, em forma de artigo expandido, do artigo curto previamente apresentado no XVII ENCONTRO NACIONAL DE TECNOLOGIA NO AMBIENTE CONSTRUÍDO, dos autores Mauro Augusto Silva Junior e Cláudio Vicente Mitidieri Filho, do Instituto de Pesquisas Tecnológicas do Estado de São Paulo. A pesquisa analisou a viabilidade de verificação automática dos critérios de desempenho de edificações habitacionais utilizando recursos nativos de ferramentas de autoria de Modelagem de Informação da Construção (Building Information Modeling - BIM). Foram identificadas vantagens em utilizar recursos de softwares de modelagem, como etiquetas, filtros de cor e tabelas para verificação de regras e requisitos. O resultado é considerado pelos autores como promissor, verificandose a possibilidade de identificar e detalhar aproximadamente um terço dos critérios constantes da NBR 15575 (ABNT, 2013); promovendo assim o desenvolvimento de projetos de arquitetura com informações sobre desempenho mais completas e confiáveis.

A partir de 2019 a revista PARC Pesquisa em Arquitetura e Construção passará à publicação contínua. Desta forma, será publicado somente um volume por ano e os artigos, assim que aprovados, serão publicados, distribuindo-se nas sessões de Artigos, Artigos de Revisão, Dossiê e Comunicações. A sessão de Artigos abrigará textos originais de estudos científicos, englobando produtos de pesquisas concluídas ou em desenvolvimento na temática da revista. A sessão de Artigos de Revisão destina-se a artigos de Revisões Sistemáticas da Literatura na temática da revista. A sessão Dossiê será composta por artigos científicos submetidos em chamadas temáticas. A sessão de Comunicações incluirá artigos expandidos de trabalhos apresentados em eventos de temática semelhante à revista, que apresentem até $30 \%$ de semelhança como o resumo expandido ou artigo curto anteriormente apresentado, assim como, de forma acumulativa, com outras fontes. Ao final do ano, serão publicados o editorial anual e a lista de avaliadores.

Aproveitamos para agradecer aos avaliadores que colaboraram com a revista no ano de 2018, sendo estes apresentados na seção Pareceristas. 


\section{Agradecimentos}

Agradecemos aos avaliadores pelo tempo despendido e valiosas considerações tecidas sobre os artigos submetidos.

\section{Referências}

ABNT - ASSOCIAÇÃO BRASILEIRA DE NORMAS TÉCNICAS. NBR-15575-1: edificações habitacionais: desempenho: parte 1: requisitos gerais. Rio de janeiro: 2013.

\section{${ }^{1}$ Letícia de Oliveira Neves}

Arquiteta Urbanista. Doutora em Arquitetura, Tecnologia e Cidade pela Universidade Estadual de Campinas. Professora Doutora na Faculdade de Engenharia Civil, Arquitetura e Urbanismo da UNICAMP. Endereço postal: Av. Albert Einstein, 951, Campinas, SP, Brasil, CEP 13.083-852.

\section{${ }^{2}$ Regina Coeli Ruschel}

Engenheira Civil. Doutor em Engenharia Elétrica e da Computação (UNICAMP). Livre Docente em Projeto Auxiliado por Computador (UNICAMP). Professora e Pesquisadora Colaboradora (FEC-UNICAMP) Endereço postal: Av. Albert Einstein, 951, Campinas, SP, Brasil, CEP 13.083-852. 